\title{
Otra versión sefardí manuscrita de El debate de los frutos y el vino*
}

En el presente artículo se edita otra versión manuscrita de la copla El debate de los frutos y el vino. Dicho texto, procedente del manuscrito Bacašot veširim ufiyutim (Oriente, quizá Turquía, ca. 1850), viene a sumarse a las dos versiones, también manuscritas de Venecia d. 1702 y Sarajevo ca. 1794, publicadas por la misma autora en su artículo «La copla sefardí de El debate de los frutos y el vino y sus ecos en la tradición oral», aparecido en Estudios sefardíes dedicados a la memoria de Iacob M. Hassán (z”l) (Madrid: CSIC, 2011), 491-524. Amén de editar y estudiar el texto, se lleva también a cabo la comparación con las dos versiones anteriores, poniendo de relieve las principales diferencias estructurales, léxicas y morfológicas, así como de cambios de formulaciones.

Palabras Clave: Literatura sefardí; coplas; manuscritos sefardíes; edición de textos sefardíes aljamiados; léxico judeoespañol.

El debate de los frutos y el vino, An Alternate Manuscript Version.- The author provides with an edition of an alternate manuscript version of the Copla El debate de los frutos y el vino. The text, included in the Baqqashot ve-Shirim u-Fiyutim (manuscript, Middle East, maybe Turkey, ca. 1850), is then added to the previous versions, one manuscript version from Venice (1702) and another one from Sarajevo (ca. 1794), that were published by the author in her article "La copla sefardi de El debate de los frutos y el vino y sus ecos en la tradición oral" published in Estudios sefardies, dedicados a la memoria de Jacob M. Hassán (z"l) (Madrid: CSIC, 2011), 491-524. Besides the edition and analysis of the text, the author compares it with the two earlier versions, highlighting the structural, lexicographical and morphological differences, as well as the changes experimented.

Keywords: Sephardic Literature; Coplas; Sephardic Manuscripts; Edition of Sephardic Texts; Judeo-Spanish Lexicon.

"El presente artículo se ha elaborado en el marco del proyecto de investigación del Plan Nacional I+D+I: «Sefarad siglo XXI (2009-2011): Edición y Estudio Filológico de Textos Sefardíes» (SGPI, MICINN, FF2009-10672 [subprograma FILO]).

***elena.romero@cchs.csic.es 
Como por desgracia casi siempre sucede en este complejo mundo de la bibliografía sefardí - ioh males de la fortuna!-, no bien he visto por fin publicado el texto de la copla El debate de los frutos y el vino que hace años entregué para el Homenaje a Iacob M. Hassán y buscando materiales en relación con el trabajo que en la actualidad tengo entre manos, me he dado de bruces con otra versión manuscrita de dicha copla, que entonces no conocía y que por tanto no tuve en cuenta en mi edición ${ }^{1}$.

Los materiales entonces usados fueron dos versiones manuscritas: la del Séfer širot vetušḅahot (o Ne ím źemirot) (Venecia 1702 y ss.) fols. $157 \mathrm{v}-158 \mathrm{v}$ y $153 \mathrm{r}$ (abrev. V702) ${ }^{2}$, cuyo iniciador fue Mošé ben Mijael Hakohén (Salónica o Sarajevo 1644 - Venecia ca. 1726); y la del Piźmonim veširot vetišḅahot (Sarajevo 1794 - Venecia) fols. 152r$153 \mathrm{v}^{3}$ (abrev. Sr794), compilado por David Bajar Mošé Hakohén. Allí también me ocupaba de los restos por mí conocidos presentes en la tradición oral.

En plan premonitorio -yo diría que agorero- en mis conclusiones en Debate (p. 523) decía que entre las versiones manuscritas de V702 y Sr794 y las muestras orales modernas:

[...] indudablemente tiene que haber eslabones perdidos en la cadena de transmisión de la copla que, si bien yo hasta ahora no he encontrado, han, sin duda, de aparecer o al menos eso espero fervientemente (y ojalá que ello sea dentro de poco y no dentro de otros tantos siglos, ya que entonces tendrán que venir a contármelo los pajaritos).

Pues bien, parece que los hados -siempre entrometidos- han escuchado mi no sé porqué tan ferviente ruego y, a destiempo y a deshora, me han hecho aflorar esta otra furtiva y «redescubierta» versión, cuya fotocopia ha estado durmiendo en mi casa desde no sé hace cuánto tiempo para aparecer inopinadamente ahora y darme el consiguiente susto. Tal versión figura en

1 Vid. Elena Romero, «La copla sefardí de El debate de los frutos y el vino y sus ecos en la tradición oral», en Elena RoMERo - Aitor GARcía Moreno (eds.), Estudios sefardíes dedicados a la memoria de Iacob M. Hassán (z”l) (Madrid: CSIC, 2011) pp. 491-524. Abrev. Debate.

${ }^{2}$ He manejado reproducción del original de la British Library (Londres), Add. 26967. Sobre el manuscrito vid. Debate nota 1.

${ }^{3}$ He usado reproducción del original de la National Library of Israel (Jerusalén) (abrev. NLI) Heb. $8^{\circ}$ 413. Sobre el manuscrito vid. Debate nota 2. 
el manuscrito Bacašot veširim ufiyutim (Oriente, quizá Turquía, ca. 1850) ${ }^{4}$ fols. 9a-14a (numeración hebrea 39a-44a) (los dorsos en blanco) (abrev. msOr850?), cuya fecha es sólo tentativa. El manuscrito está en letra raší sin vocalizar y su grafía se presenta normalizada, de ahí mi datación tardía.

En Glosario al final del artículo recojo solo el léxico que no aparecía en Debate.

\section{EDICIÓN DEL TEXTO}

Puesto que los textos manuscritos de V702 y $S r 794$ ya circulan en mi citada edición, resulta innecesario volverlos a repetir aquí. Sin embargo, para facilitar al interesado la comparación, marco en cursiva las variantes con V702 y los corchetes suponen supresión de algún elemento de ese texto base; entre barras inclinadas indico la única palabra escrita sobre la línea.

Teniendo en cuenta que, como luego indicaré, a partir de la estr. núm. 7 el orden de estrofas es muy diferente entre la actual versión y las de V702 y Sr794, cabe advertir lo siguiente: en mi edición los primeros números corresponden a los de orden de Or850?, y van seguidos, tras barra inclinada, de los correspondientes de las estrofas de $V 702$ y de $S r 794$; la ausencia del tercer número implica igualdad en el orden de esos dos manuscritos y con 0 indico la omisión de la estrofa en $S r 794$.

Veamos ya el texto de Or850?

1 Demandóme mi amigo:

«Si tenes [] memoria

$a$ [] haćer lo que te digo:

a las frutas una historia;

si queres estar conmigo

y tomar gusto y loria,

que en cada fruta y fruta

es de alabar a el vino».

2 Respondióme $e^{5}$ «[] Mi querido, yo haré recibio ${ }^{6}$.

${ }^{4}$ Uso fotocopia del ejemplar del Jewish Theological Seminary of America (NuevaYork) (abrev. JTSA), Enelow Memorial Collection 2296.

${ }^{5}$ Sobre la falta de correspondencia entre el Demandóme de v. 1a y este Respondióme, que de forma algo parecida también sucedía en V702, vid. ROMERo Debate nota 5.

${ }^{6}$ Parece escrito ריסיביו; vid. infra aprt. 2.3. 
¡Así te vea parido!, que tomes gusto y vicio; que sepas que so sabido y sé muncho artificio, en cada copla y copla que atemen [] con el vino».

3 La /lechuga/ es [] hermośa, tamién comida galana; y es fresca y donośa, sobre todo es cośa sana, $\mathrm{y}$ es fruta muy galana que haće abrir la gana, mas quere con miel de rośa y con vinagre de vino.

4 La segunda es la habica y primera de las frutas; []

[]

se haće buena cenica y tamién pasa [] fruta; y encima no vale agua, sino todo beber vino.

5 La cereźa, mi hermano, tiene sabor y color; cuando me entra en la mano, yo la como sin dolor.

Antes que le venga el guśano y le quite la sabor, asentemos, mis hermanos, y roćialmeldas ${ }^{7}$ con vino.

6 La višnica es más agrica y con ella hermanada, y es fruta muy buenica y conserva estimada; el ḥošap con cucharica es cośa muy alabada,

\footnotetext{
${ }^{7}$ Lectura dudosa.
} 


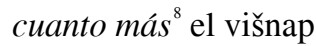

es muncho mejor que el vino.

7 Me agrada, mi hermano, la alveanica de tiria ${ }^{9}$. ¡Así crezcas como el trigo y tengas muncha alegría! $!^{10}$ ¡así yiva yo contigo y no veamos [] manćía!, que hagas lo que te digo y no las comas sin vino.

8/20/0 Si dećíš por la acraña ${ }^{11}$, de comerla no es trato, que traba como la cacia ${ }^{12}$, [] haće la boca zapato; amá tiene otra maña: de haćerla acrañato, que corta el mahmurlic y demanda a chuflar vino.

9/24/0 Linda es la agranada y su vista muy galana; por [] es alabada: porque se come sin gana; $y$ la [] es mentada, sobre todo es cośa sana; [] la fresca y la escaldada con ella se bebe $e l$ vino.

10/13 El šeftilí respondióles: «Más grande [] la mi fama;

${ }^{8}$ Tachado detrás «con cucharica», probablemente por salto de ojo a las palabras finales de v. 6e.

${ }^{9}$ Escrito טייר, que supongo un error gráfico por lo que en V702 era trilla, ya que no creo que nuestro manuscriba esté pensando en Tiria.

${ }^{10}$ Ante el verso dos palabras tachadas ilegibles.

${ }_{11}$ Ante la estrofa y tachado: «Si dećís por la acraña / de comerla en la güerta / tamién con la señora / que retorna alma muerta», siendo los tres últimos versos un anticipo de Or 850 ? estr. 14 (= estr. 10 de V702), si bien el v. 14 c presenta una variante con respecto a este.

12 Escrito קאסייה. 
que mis golores golió a él le retorna [] alma; y la novia con el novio por gozos amores ama Asentemos yo y vos, y comámolas con [] vino.

11/11 Respondió el caisí:

«Yo so cośa muy valiente;

deśde que yo nací

me envían por preśente;

y tamién yo alcancí

a estar denlantre de [] ĝente

con mi tío Chirasí

que le agrada chuflar vino».

12/8 La pera, para [] gente, es mejor la boźdogán; la ${ }^{13}$ mirindí a el pariente [] enyialda por armagán; la šequierí al doliente; la yocsoi ${ }^{14} a$ el haragán; la burnusús a el valiente, es mejor $^{15}$ para el vino.

13/23 Los higos a la hartura dan ciciones [] valientes y fríos ${ }^{16}$ y caenturas, [] tamién escruje los dientes.

No veas tal amargura ni tú $n i$ tus parientes, porque yo tuve ventura y las saydeí con vino.

14/10 Si preguntáš por la mora, [] de comerla en la güerta; $\hat{j}$ untos con la señora

\footnotetext{
${ }^{13}$ El artículo la repetido y tachado.

${ }^{14}$ Escrito יוקסוי; vid. mi comentario en el aprt. 2.2.

${ }^{15}$ Pero parece estar escrito מיזיוס mejos.

${ }^{16}$ Ante frios tachado algo ilegible.
} 
que retorna alma muerta.

Cuánto más que se namora

cuando es la mora preta;

$y$ su caldo en su hora

es muncho mejor que el vino.

15/12 La ćirgüela es más agrica, sino que yolta los dientes;

envialda ${ }^{17}$ con damas

$a$ primas y $a$ parientes;

los señores y las damas

todos los tienen en mientes

$y$ de adientro de sus []

porque les corta el vino.

16/18 La granada es ansí:

es cośa muy alabada;

oí dende [] nací

que la haćen [] conservada.

Asegún lo que pensí,

me convidéš granada;

tú da, yo diré sí

con raquí y no con vino.

17/9 La manzana es mentada

en sabor y en golor;

[] en el árḅol alabada, si en fruto, si en flor; todo el tienpo es hallada $s i$ en frío, si en calor, tamién es muy estimada para el bebedor de vino.

18/15 «Yo, carpuz de Lapsekí, de aquel lugar mentado, a todos arefresquí, amarío y colorado.

Alevanta [] de aquí, no asentes a mi lado porque yo corto [] raquí y so enemigo de el vino».

${ }^{17}$ Tras la palabra y tachado: «por preśente a», quizá salto de ojo a v. 11d. 
19/16 El melón le respondió:

«Yo te dije de enfrente:

que vino crió el Dio

para alegrar a la gente.

De tu lado se fuyó,

[] se asentó de enfrente;

enpero lo llamo ${ }^{18}$ yo,

que con mí se bebe $e l$ vino».

20/14 El pepino es hermośo,

cortaldo antes $d e^{19}$ el día

y se haće más hermośo

meteldo sal de Vlahía;

y comerlo con repośo,

y tamién con corteśía

y con alegría y goźo

[] tamién [ ]lamo ${ }^{20}$ el vino.

21/17 El limón, su primo hermano,

[] un poco y demaśiado,

que lo tomáš en la mano

y alabáš a el Aḅastado;

[] de el doliente y de el sano

de todos es alabado

azúcar polvoreado;

enpero corta el vino.

22/19 La mueź, en cośa de masa,

[] esculacha y macarones;

tamién con hạardal y prasa

es comida de varones;

[] se haće almuaza

con almendras y piñones,

[] sin ello no se pasa,

y con ella se bebe el vino.

23/22/21 De la múšcula no te hartes

porque te dará durera;

${ }^{18}$ La palabra llamo repetida.

${ }^{19}$ Las palabras antes de están repetidas.

${ }^{20}$ Me resultan ilegibles las tres primeras letras de la palabra, que podrían ser: álef, quizá yod y una letra con tilde encima, que no sé si es bet o pé; vid. infra aprt. 2.3. 


\author{
[] \\ en tu güerta no la sembres \\ ni tú ni tu conpañera; \\ y si de ella te hartares, \\ las despedirás con vino. \\ 24/21/20 En la meśa odrenada \\ es buena la castañanica ${ }^{21}$; \\ cuanto más es alabada \\ cuando está bien asadica, \\ en el horno aćeitada, \\ se haće una ${ }^{22}$ cośa rica \\ $y$ por esto les agrada \\ a los bebedores de vino.
}

\title{
2. EsTUDIO
}

\subsection{Características formales de Or850?}

Como ya decía en Debate (p. 503), en la versión más antigua (V702) la copla lleva el título de «Coplas min haperot» ( $h b$. '... de las frutas') y consta de 26 estrofas, 25 formadas por ocho versos con tendencia a ser octosílabos y de rima que tiende a ser $a b a b a b a c$, quedando en ocasiones suelto el verso séptimo, y una más, la última, con el mismo número de versos que tienden a ser monorrimos. El último verso de todas las estrofas acaba siempre con la palabra vino. Por su parte, la otra versión (Sr794) lleva por título «Cantiga de las frutas» y consta de 24 estrofas con la misma estructura métrica.

El texto que ahora estudiamos, que responde a la estructura descrita, lleva por cabecera: «Cantiga de las fruta [sic]», coincidiendo con $\mathrm{Sr} 794$, y consta de 24 estrofas en las que encontramos numerosos cambios en relación con las otras dos versiones señaladas, cambios de los que luego me ocupo.

En Or850? los versos van en línea seguida sin separación. Un adornito suele servir de remate a las estrofas, que repetido y en pirámide invertida $-5,3,2,1-$ también figura al final del texto.

\footnotetext{
${ }^{21}$ Así escrito; precede a la palabra un tachón en el que sólo leo el principio casta[].

${ }^{22}$ La lectura de una es dudosa.
} 
Como he ido señalando en las notas a la edición, hay bastantes tachaduras $^{23}$ y una adición supralineal, todo ello producto de correcciones del manuscriba al advertir sus errores de copia.

La adición supralineal es la de la palabra lechuga en «La /lechuga/ es hermośa» (v. 3a). En cuanto a algunos tachones -los que puedo leer-pueden explicarse mayoritariamente por saltos de ojo del manuscriba, quien elimina lo repetido ${ }^{24}$, y en un caso por repetición de dos palabras consecutivas, eliminada una de ellas ${ }^{25}$. Sin embargo, también encontramos otras repeticiones que el manuscriba no ha advertido y en consecuencia no ha tachado ${ }^{26}$.

\subsection{Contenido y estructura de Or850?}

No hace falta repetir aquí el contenido y estructura general de la copla, ya detallados en mi anterior estudio (Debate pp. 508 y ss.), pero sí precisar los cambios que encontramos entre esta versión y las dos anteriores.

En relación con $V 702$ se omiten en $O r 850$ ? las estrs. 25-26 -la última tampoco estaba en $S r 794-$, y tampoco tiene la nueva y última estrofa de Sr794 (su estr. 24). Sin embargo, sí figuran aquí las estrs. 20 (= 8) y 24 (= 9) de $V 702$, perdidas en $S r 794$. Además nuestro texto pierde los vs. 4c-d de $V 702$ y dos versos de 23 (=22).

Coincide $\operatorname{Or} 850$ ? con las dos versiones más antiguas en la ordenación de estrs. 1-7; pero a partir de aquí el texto se reestructura como sigue (el primer número corresponde siempre al de esta nueva versión y el segundo al de $V 702)^{27}: 8=20,9=24,10=13,11=11,12=8,13=23,14=10$, $15=12,16=18,17=9,18=15,19=16,20=14,21=17,22=19,23$ $=22$ y $24=21$.

Como en V702 y en $S r 759$, tras las dos estrofas de inicio se desarrolla el núcleo del poema, formado ahora por las señaladas 24 , sin que en esta

${ }^{23}$ Vid. notas 8, 10-11, 13, 16-17 y 21.

${ }^{24}$ Vid. notas 8, 11 y 17.

25 Vid. nota 13.

26 Vid. notas 18-19.

${ }^{27}$ No parece necesario indicar aquí las estrofas de $\operatorname{Sr} 794$, ya que salvo la pérdida de las estrs. 20, 24 y 26 de V702 y la adición de una nueva al final, sigue siempre la ordenación estrófica del texto más antiguo. 
versión aparezca ninguna estrofa de cierre, acabando el texto abruptamente.

En cuanto a las frutas y verduras mencionadas en los primeros versos de las estrofas, figuran en Or850? un total de 22, que son las siguientes: lechuga (estr. 3), haba (estr. 4), cereza (estr. 5), guinda (višna, estr. 6), avellana (estr. 7), cornejo (acraña, estr. $8 /=20$ ), agranada / granada (estrs. 9 y $16 /=24)$, melocotón (̌̌eftilí, estr. $10 /=13$ ), albaricoque (caisí, estr. $11 /=11$ ), pera (estr. $12 /=8$ ), higo (estr. $13 /=23 / 22)$, mora (estr. 14 / = 10), ciruela (estr. $15 /=12)$, manzana (estr. $17 /=9)$, sandía (carpuz, estr. $18 /=15)$, melón (estr. $19 /=16)$, pepino (estr. $20 /=14$ ), limón (estr. $21 /=17$ ), nuez (estr. 22 / = 19), múšcula cierto tipo de baya (estr. 23 / = 22 / 21) y castaña (estr. $24 /=21 / 20)$.

Conviene señalar las mayores diferencias con los manuscritos anteriores en este repertorio de frutas. Como vemos encontramos aquí una fruta repetida, la granada (estrs. 9 y 16), correspondiendo lo que se dice de ella en estr. 16 a lo que en $V 702$ (estr. 18) se decía de la naranja, fruta que en Or850? no figura; la múšcula (estr. 23, tc. müş̧üle) sustituye a la serba (sorba) de la versión base (estr. 22 / 21); y, al haberse omitido la estr. 25 de $V 702$ (23 de $S r 794$ ) desaparece de nuestra versión la fundamental mención de la parra, omisión importante ya que en esa estrofa se cantan las excelencias de la fruta que produce el vino, en función del cual gira toda la copla.

Frente a ello hay que señalar que aparece una fruta nueva, camuflada en v. 8c de la estrofa dedicada al cornejo (acraña) (v. 20c de V702): se trata de la cacia (esp. acacia 'endrino, ciruela silvestre'), de la que se dice que produce estreñimiento (traba), propiedad esta que también recoge el $D R A E$.

La nueva reestructuración de estrofas provoca que en ocasiones alguna formulación no resulte del todo lógica. Tal es el caso de la estr. 17 de $V 702$ en la que habla el melón, diciendo que «es primo hermano» del limón, fruto que figura en la estr. 16, primo-hermandad que quizá, más que a otra cosa, pueda deberse a la proximidad consonántica entre las dos palabras. Pues bien, en Or850? el limón en estr. 21 resulta ser primo hermano del pepino de estr. 20 -el cual aparecía en estr. 14 de V702-, escapándoseme ahora el vínculo de parentesco entre ambos vegetales.

Comentario aparte merece la estrofa dedicada a la pera (estr. $12=$ 8 de V702), que ya suscitaba mis dudas en Debate (p. 508). Allí decía 
que en V702 se mencionan «un total de 24 frutas y verduras, mayoritariamente a razón de una por estrofa, excepto en el caso del tamarindo camuflado en la estrofa (v. 8c) dedicada a la pera». La estrofa quedaba así formulada en los dos manuscritos anteriores:

\begin{tabular}{|c|c|}
\hline V702 estr. 8 & Sr794 estr. 8 \\
\hline $\begin{array}{l}\text { La pera, para la ĝente, } \\
\text { es mejor la boźdogán; } \\
\text { y mirindí a los parientes } \\
\text { la envían por armagán; } \\
\text { la šequierí a los dolientes, } \\
\text { yo que soy el ḥaragán; } \\
\text { la burnusús, que es valiente } \\
\text { es meźé pera el vino. }\end{array}$ & $\begin{array}{l}\text { La pera, para la ĝente, } \\
\text { es mejor la de Boźdagán, } \\
\text { y merece para los parientes } \\
\text { y la enỵían por argamán; } \\
\text { y se quere para los dolientes, } \\
\text { yo que so el haragán; } \\
\text { y la burnusús es valiente } \\
\text { y es mej́or para el vino. }\end{array}$ \\
\hline
\end{tabular}

Y en mis explicaciones léxicas en notas 13-16 de Debate precisaba lo siguiente, palabras que no tengo más remedio que repetir aquí.

En relación a boźdogán: «Variedad de pera (cfr. tc. bozdă̆an, bozdoğan armudu), originaria del pueblo de Bozdoğan, al sudoeste de Anatolia». Sobre mirindí: «Dado el contenido de vs. 8b, 8e y 8g, en los que se mencionan otras tres variedades de peras [...], habríamos esperado también aquí la mención de alguna otra variedad de dicho fruto y no la aparición de un inopinado tamarindo (tc. demirhindi), del que Nehama Dictionnaire s.v. demirindi dice "[...] qu'on emploie comme purgatif", precisando además “On dit souvent merendi”». Para šequierí: «Alguna variedad de pera especialmente dulce (cfr. tc. şeker 'azúcar' y şekerî 'con azúcar, azucarado’)». Y en relación con burnusús: «Supongo que se refiere a otra variedad de pera, chata o sin rabo (cfr. tc. burunsuz 'sin nariz, sin punta')».

Como vemos, en $\mathrm{Sr} 794$ las tres variedades de peras han quedado reducidas a dos - «la de Boźdagán» (v. 8b) y «la burnusús» (v. 8g) y ha desaparecido el tamarindo.

Pues bien, en la nueva formulación de Or850? esto es lo que leemos:

12 La pera, para gente, es mejor la boźdogán;

la mirindí a el pariente 


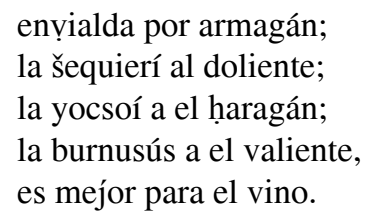

Según ello, las variedades de pera, tamarindo incluido, que aquí figuran son cinco, cuatro de ellas ya conocidas: «la boźdogán», preferida de la gente (v. 12b); «la mirindí», que se manda al pariente (v. 12c); «la šequierí», apropiada para el doliente (v. 12e); y «la burnusús», que ahora corresponde al valiente (v. 12g), quedando muy claro en las nuevas formulaciones a quién corresponde cada variedad. Pues bien, a estas se añade ahora otro curioso tipo de pera -«la yocsoì propia del haragán (v. 12f)-, palabra que hay que entender como fruto de una ingeniosa interpretación del «yo-quesoy» de $V 702$, quedando así convertida en una nueva variedad de pera, sustantivada por el pertinente artículo, la nada clara formulación de $V 702$ «yo que soy el ḥaragán», que no venía a cuento en el contexto de la estrofa.

\subsection{Cambios léxicos}

En cuanto al léxico -amén de los cambios ya indicados en relación con los frutos- encontramos en Or850? las esperables fluctuaciones propias de la variabilidad del léxico judeoespañol, todas ellas de menor cuantía desde el punto de vista literario y de las que no voy a ocuparme.

Encontramos también algunos errores obvios. Tal es el caso de: «yo haré recibio» (v. 2b) frente a «(yo) estó pronto a tu servicio» de V702 y Sr794; que (v. 10c) en lugar de quien / quen de V702 y Sr794 (v. 13b); castañanica (v. 24b) en lugar de castañica de V702 (v. 21b) y $S r 794$ (v. 20b); y «tamién []lamo el vino» (v. 20h) frente a «alabá(d) tanbién el vino» de $V 702$ y $S r 794$ (v. 14g).

En relación con el léxico turco, es interesante destacar las diferencias que observamos entre las tres versiones, mostrándose nuestro texto más próximo a $V 702$ que a $S r 794$ en sus formulaciones. Así: (v. 2h) atemen (cfr. hb. תם tam 'acabar, finalizar') 'acaben' (Or850? / V702) / bitrearé (tc. bitir- 'acabar, terminar') 'acabaré' (Sr794); (v. 6a) agrica (Or850?) / agrita (V702) / mayošica (cfr. tc. mayhoş 'agridulce', dim.) 'agridulcita' (Sr794); (12b / 8b) Boźdogán (Or850? / V702) / Boźdagán (Sr794) para el topónimo Bozdoğan; (10a / 13a) šeftilí (Or850? / V702) / šoptilí (Sr794) 
(tc. şeftali) 'melocotón'; y (18a / 15a) carpuz (Or850? / V702) / carpuź

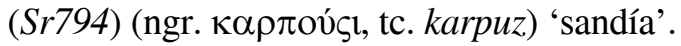

Frente a ello, en un par de casos Or850? coincide con $S r 794$ y no con V702; así en: (v. 11a) cayisí (V702) / caisí (Sr794 / Or850?) (tc. kayısı) 'albaricoque'; y en la sustitución (v. 12h / Sr794 v. 8h) del meźé (tc. meze) 'aperitivo' de V702 (v. 8h) por mejor, si bien y como indico en mi edición (nota 15) al estar escrita la palabra mejos en Or850?, podría tratarse de un mero error gráfico que camufle el meźé original. En alguna otra ocasión también sucede que nuestro manuscrito no coincide con ninguno de los dos anteriores: (v. 18a / 15a) Lapsekí (Or850?) / Lapsakí (V702) / Lovsakí (Sr794) para el topónimo Lâpseki.

Además aparecen en nuestro manuscrito turquismos nuevos o diferentes a los que figuraban en V702 y en $S r 794$, por ejemplo: amá (tc. ama 'pero') (v. 8e / 20e), que sustituye al más de V702; maḥmurlic (tc. mahmurluk) 'resaca después de una borrachera' (v. 8g/20g), según lo cual eso es lo que elimina (corta) el acrañato, probablemente zumo de la acraña (tc. karani-

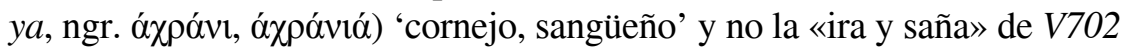
(dichas estrofas no aparecen en Sr794); y la ya aludida baya múšcula (tc. müşküle) (estr. 23 / = 22 / 21), que sustituye a la sorḅa (esp. sorba, serba) de las anteriores versiones.

Frente a Sr794, mantiene de V702 los abstrusos mirindí (v. 12c / 8c), que $S r 794$ transforma en merece, y almuaza (v. 22f / 19f), que Sr794 torna en mezclanza. De la palabra almuaza ya decía en Debate (nota 33) que no tenía clara su etimología, aunque apuntaba la posibilidad de que se tratara de un derivado de la forma sefardí almuez 'nuez' (recogida por Nehama Dictionnaire s.v. almwéz), para referirse a una pasta a base de nueces. Y asimismo mantiene (v. 13h / 23h) el castizo šaydeí (cfr. esp. insípido, jauto) que $\operatorname{Sr} 794$ cambia en paidi ${ }^{28}$.

Encontramos también en Or850? cambios en el léxico hispánico, como las sustituciones de gusto por gozo (v. 1f); encima por enriba (v. 4g); buenica por el raro donica (v. 6c); chuflar por beber ${ }^{29}$ (11h / 11h y 20h / 8h); higos por figos y fartura por hartura (v. 13a / 23a / 22a); la ya mencionada granada por naranja (16a / 18a), lo que obliga a que la bebida que se solicita en v. 16 f (18f) sea granada, supongo que el zumo de tal fruta, y no la

\footnotetext{
${ }^{28}$ Sobre la palabra vid. Debate nota 40.

29 Tal significado lo recoge también Nehama Dictionnaire s.v. čuflár.
} 
naranjada de V702 y de Sr794; alabada (v. 16b) en lugar de enlevada de V702 (v. 18b) y del más raro arlebada de $S r 794$; y mentada (v. 17a) por el estimada de $V 702$ y $S r 794$ (v. 9a), si bien en el v. $17 \mathrm{~g}$ de esa misma estrofa encontramos el cambio al revés: estimada por enmentada.

2.4. Cambios morfológicos que afectan a elementos verbales y sustantivos

Encontramos los siguientes.

- Diferentes personas, tiempos y modos verbales ${ }^{30}$

1b Si tenéš buena memoria / = / Si tenes memoria

1e si quieréš estar conmigo / si queres estar conmigo / si queres estar conmigo

7f y no vea tu manćilla / = / y no veamos mancía

1h has de alabar al vino / = / es de alabar

8d la envían por armagán / = / 12d enyialda por armagán

14 b cortarlo antes del día / cortado antes del día / 20 b cortaldo antes de el día

16b Yo te digo de enfrente / = / 19b Yo te dije de enfrente

$18 \mathrm{f}$ me conyidáš naranjada / = / 16f me convidéš granada

20f que después de hecho acrañato / 0 / 8f de haćerla acrañato

23d y tanbién crujir de dientes / 22d y tanbién duelen los dientes / 13d tamién escruje los dientes

- Omisión y adición de verbos

1c has de haćer lo que te digo / = / a haćer lo que te digo

$10 \mathrm{~b}$ es de comer en la güerta / = / 14b de comerla en la güerta

13b Más grande es la mi fama / = / 10b Más grande la mi fama

3d sobre toda cośa sana $/=/$ sobre todo es cośa sana

14c con la sal de Vlahía / = / 20c meteldo sal de Vlahía

18a La naranja en sí / = / 16a La granada es ansí

${ }^{30}$ En todos los ejemplos que siguen no pretendo ser exhaustiva. La primera formulación es siempre la de $V 702$, la segunda corresponde a $S r 794$ y la tercera a $\operatorname{Or} 850$ ?; con signo = indico que la formulación de $S r 794$ es idéntica o muy similar a la de $V 702$ en el fenómeno del que me estoy ocupando, y con 0 marco que la estrofa se omite en $\mathrm{Sr} 794$. Señalo en cursiva las palabras que afectan a los fenómenos que comento. 
- Omisión, adición y cambios de pronombres

$2 \mathrm{~h}$ atemen toda[s] con vino / bitrearé con el vino / que atemen con el vino

11a Respondióle el cayisí / = / Respondió el caisí

15e Alevanta tú de aquí / = / 18e Alevanta de aquí

$16 f$ y me se asentó enfrente $/=/ 19$ f se asentó de enfrente

$24 \mathrm{c}$ por esto es alabada / $0 / 9 \mathrm{c}$ por es alabada

5e Antes que venga el guśano / = / Antes que le venga el guśano

$10 \mathrm{~b}$ es de comer en la güerta / es de comerla en la güerta / 14b de comerla en la güerta

2a Respondióle: El mi querido / = / Respondióme: Mi querido

11c desde que me conocí / = / deśde que yo nací

11d a mí envían por preśente / me enṿían por preśente / me envían por preśente

13a El šeftilí les respondió / = / 10a El šeftilí respondióles

- Omisión de sustantivos

19b aletría y esculacha y macarones / es cośa muy valiente / 22b esculacha y macarones

- Diferencias de número en sustantivos

$5 \mathrm{~g}$ ajuntemos, mi hermano / $=/$ asentemos, mis hermanos

$8 \mathrm{c}$ y mirindí a los parientes $/=/ 12 \mathrm{c}$ la mirindí a el pariente

$8 \mathrm{~d}$ la šequierí a los dolientes / $=/ 12 \mathrm{~d}$ la šequierí al doliente

$23 \mathrm{c}$ y frío y callentura $/=/ 13 \mathrm{c}$ y fríos y caenturas

- Omisión y adición de adjetivos

1b Si tenéš buena memoria / = / Si tenés memoria

$7 \mathrm{~d}$ y tengas alegría / = / y tengas muncha alegría

- Omisión y adición de artículos

8a La pera, para la ĝente / = / 12a La pera, para ĝente

$11 \mathrm{f}$ a estar entre $l a$ ĝente $/=/ 11 \mathrm{f}$ a estar delantre de ĝente

13d a él le retorna $\mathrm{el} \mathrm{alma} \mathrm{/}=/ 10 \mathrm{~d}$ a él le retorna alma

13h goćémolos con el vino / goźómelos con vino / 10h y comámolas con vino 
$2 \mathrm{~h}$ atemen toda[s] con vino / bitrearé con $e l$ vino» / que atemen con $e l$ vino»

6h es mucho mejor que vino / $=$ / es muncho mejor que $e l$ vino

24h con ella se bebe vino / $0 / 9 \mathrm{~h}$ con ella se bebe $e l$ vino

- Cambios de artículos por pronombres y viceversa

1a Demandóme un amigo / = / Demandóme mi amigo

6e $s u$ ḥošap con cucharica / = / el ḥošap con cucharica

- Omisión y cambio de preposiciones, adverbios y conjunciones

$2 \mathrm{~g}$ que cada copla y copla / = / en cada copla y copla

3a La lechuga es muy hermośa / La lechuga es alabada / La lechuga es hermośa

4f y tanbién pasa por fruta $/=/ \mathrm{y}$ tamién pasa fruta

8c $y$ mirindí a los parientes $/=/ 12$ c la mirindí a el pariente

$11 \mathrm{f}$ a estar entre la gente $/=/$ a estar delantre de gente

$13 \mathrm{e}$ tanbién novio con novia / $=/ 10 \mathrm{e} y$ la novia con el novio

$18 \mathrm{c}$ oí desde que nací / = / 16c oí dende nací

20d $y$ hace la boca zapato / $0 / 8 \mathrm{~d}$ hace la boca zapato

$20 \mathrm{f}$ que después de hecho acrañato / 0 / 8f de haćerla acrañato

$23 \mathrm{~b}$ dan ciciones muy valientes $/ 22=/ 13 \mathrm{~b}$ dan ciciones valientes

23d y tanbién crujir de dientes / y tanbién duelen los dientes / 13d tamién escruje los dientes

24b y su vista bien galana / $0 / 9 \mathrm{~b}$ y su vista muy galana

24g $y$ la fresca y la escaldada / 0 / 9g la fresca y la escaldada

- Adición de conjunciones y preposiciones

2h atemen toda[s] con vino / bitrearé con $e l$ vino / que atemen con el vino

$15 \mathrm{~b}$ aquel lugar enmentado $/=/ 18 \mathrm{~b}$ de aquel lugar mentado

$20 \mathrm{~g}$ corta ira y saña / 0 / 8g que corta el mahmurlic

- Cambio de orden en las palabras

$4 \mathrm{~b}$ tiene golor y sabor / tiene color y sabor / tiene sabor y color

$13 \mathrm{~g}$ Asentemos vos y yo $/=/ 10 \mathrm{~g}$ Asentemos yo y vos 


\subsection{Cambios de formulaciones}

Mayor importancia desde el punto de vista literario tienen determinadas reformulaciones de $\operatorname{Or} 850$ ? frente a $V 702$ y a $S r 794$. Veamos algunas de ellas.

Al ocuparme en mi anterior estudio de la versión de V702 (pp. 513 y ss.) ya ponía de relieve los varios defectos de su texto y señalaba los cambios de $\mathrm{Sr} 794$ en relación a los siguientes aspectos: 1) recomposición de rimas; 2) recomposición de versos cortos; 3) sustitución de palabras o de frases no comprensibles; amén 4) de otros cambios menos justificados. Sigo aquí el mismo sistema.

Pero antes de seguir adelante quiero señalar lo que ya se ha podido ver en los ejemplos que anteceden y volverá a advertirse en los siguientes, es decir, que comparando los tres textos resulta evidente que, en cuanto a formulaciones, Or850? está más próximo al manuscrito más antiguo, no sumándose a los muchos y profundos cambios que figuran en la versión de Sarajevo frente a la veneciana.

Sin embargo y por lo que tiene de singular me parece interesante dejar constancia de un caso en el que nuestro manuscrito está más próximo a Sr794 que a V702. Se trata del verso de V702 «que el Pésah sin ello no se pasa» (v. 19g), que ya en $S r 794$ había pasado a ser «que sin ello no se pasa», y que ahora se formula «sin ello no se pasa» (v. 22g). Como ya decía en Debate (pp. 511 y 515), con tal cambio desparece la única alusión a asuntos judíos que figura en la copla.

\subsubsection{Recomposición de rimas}

En relación con las rimas defectuosas, encontramos variantes encaminadas a eliminar, con mayor o menor éxito, duplicidades en las palabras de rima de una misma estrofa y también a arreglar rimas deterioradas.

En cuanto a lo primero, no resuelve $O r 850$ ? en sus vs. 20a y 20c con hermośo la duplicidad de $V 702$ en los versos paralelos 14 a y $14 \mathrm{c}$, donde la palabra de rima es en ambos casos sabrośo; sí lo hacía $S r 794$ con sus sabrośo y gustośo. 
Más numerosos son los ejemplos de arreglo de rimas deterioradas. Aunque con distinta palabra que $S r 794$, recompone Or850? en v. 6a con su agrica la rima en -ica de versos impares; también en su v. 10e al cambiar de lugar -lo mismo que $S r 794-$ las palabras novio y novia de $V 702$ (v. 13e) reajusta la rima de versos impares en -io[-ió]; y en su v. $24 \mathrm{e}-\mathrm{y}$ también coincidiendo con Sr794- arregla con su aćeitada la rima de los versos impares en -ada de V702 (21e).

Como más claro ejemplo de arreglo de rimas puedo citar la estr. 12 sobre la pera, de la que ya me he ocupado arriba (aprt. 2.2), en donde encontramos en todos los versos impares la buena rima en -ente, que falla tanto en V702 como en Sr794 (estr. 8). Más abajo comento otro caso de mejora textual en materia de rimas al ocuparme de la descompuesta estr. 17 de $V 702$.

Sin embargo, Or850? con sus frutas no recompone en v. 4 b la rima en -uta de versos pares, rima que puede haber perdido de vista nuestro manuscriba al haber desaparecido de su texto algunos versos, ni en v. 7a la rima de versos impares en -igo, lo que en ambos casos sí hacía $S r 794$.

Los esfuerzos por recomponer rimas resultan con frecuencia baldíos, tanto en Sr794 como en $\operatorname{Or} 850$ ?, como sucede en la siguiente estrofa:

\begin{tabular}{|c|c|c|}
\hline V702 estr. 3 & Sr794 estr. 3 & Or850? estr. 3 \\
\hline $\begin{array}{l}\text { La lechuga es muy hermośa, } \\
\text { tanbién comida galana; } \\
\text { y es fresca y rośada, } \\
\text { sobre toda cośa sana, } \\
\text { y es fruta muy galana } \\
\text { que haće abrir la gana; } \\
\text { mas quiere con miel de rośa } \\
\text { y con vinagre de vino. }\end{array}$ & $\begin{array}{l}\text { La lechuga es alabada, } \\
\text { también comida galana; } \\
\text { fresca, bien arancada, } \\
\text { sobre toda cośa sana, } \\
\text { y es fruta muy galana } \\
\text { que haće abrir la gana, } \\
\text { y mucho mejor en salata } \\
\text { con vinagre fuerte de vino. }\end{array}$ & $\begin{array}{l}\text { La /lechuga/ es hermośa, } \\
\text { tamién comida galana; } \\
\text { y es fresca y donośa, } \\
\text { sobre todo es cośa sana, } \\
\text { y es fruta muy galana } \\
\text { que haće abrir la gana, } \\
\text { mas quere con miel de rośa } \\
\text { y con vinagre de vino. }\end{array}$ \\
\hline
\end{tabular}

Aquí en el caso de nuestro manuscrito, por mucho que en v. $3 \mathrm{c}$ en lugar del rośada de V702 se escriba donośa (rima en -ośa de v. 3a, que en V702 reaparece en v. $3 \mathrm{~g}$ ), la estrofa continúa descompuesta, ya que queda sin arreglar el galana de v. 3e y la secuencia en una misma estrofa de tres versos consecutivos (3d-f) con la misma rima.

Y lo mismo cabe decir de la estr. 15 paralela de V702 estr. 12, de la que luego me ocupo (aprt. 2.5.5), en la que la descomposición de la rima 
en los versos impares de $V 702$ solo la salva $S r 794$, repitiéndose además en nuestro manuscrito la misma palabra de rima damas en vs. $15 \mathrm{c}$ y $15 \mathrm{e}$.

Añade además Or850? otros estropicios en rimas que eran correctas en V702. Así por ejemplo en v. 13c su caenturas estropea la rima en -ura de los versos impares de V702 (estr. 23). Y en v. 10a con su respondióles estropea la rima en -ió de los versos impares de V702 (estr. 13).

Y como ejemplo más significativo de deterioro estrófico cabe añadir la siguiente estrofa:

\begin{tabular}{|c|c|c|}
\hline V702 estr. 22 & Sr794 estr. 21 & Or850? estr. 23 \\
\hline $\begin{array}{l}\text { De la sorba no te hartes } \\
\text { porque da mucha durera; } \\
\text { de la poca no te espantes } \\
\text { ni tú ni tu conpañera; } \\
\text { en tu güerto no la plantes } \\
\text { ningún modo ni manera } \\
\text { y si de ella te fartaras, } \\
\text { has d'espedirla con vino. }\end{array}$ & $\begin{array}{l}\text { De la sorḅa no te hartes } \\
\text { porque te dará durera; } \\
\text { de la poca no te espantes } \\
\text { ni tú ni tu compañera; } \\
\text { ni en tu güerta no la plantes } \\
\text { ningún modo ni manera } \\
\text { y si de ella te hartastes, } \\
\text { la paiderás con el vino. }\end{array}$ & $\begin{array}{l}\text { De la mušcula no te hartes } \\
\text { porque te dará durera; } \\
\text { [] } \\
\text { en tu güerta no la sembres } \\
\text { ni tú ni tu conpañera; } \\
\\
\text { y si de ella te hartares, } \\
\text { las despedirás con vino. }\end{array}$ \\
\hline
\end{tabular}

En tal estrofa, amén de la desaparición del v. 22c de V702, encontramos además en Or850? trasladado de lugar el v. 22d de la base, y con su sembres se da al traste con la rima en -tes de versos impares.

\subsubsection{Arreglo de formulaciones}

Otros de los problemas de V702 son: a) los varios versos muy cortos; y b) el caso de su estr. 17, descompuesta de rima y de medida de los versos, en la que se hace difícil rastrear su estructura original.

En relación con lo primero, en todos los casos $-\mathrm{y}$ de forma diferente a como lo hace $S r 794-$ se subsanan en esta nueva versión los versos que en V702 quedaban cortos: 4h, 6g, 8a (=20a), 17h (=9h) y 22h (=19h).

Veamos en qué consisten tales cambios. Bajo la columna de V702 indico los números de sus estrofas y bajo Or850? los correspondientes cambios de numeración, cuando los hay. Para la presentación de los ejemplos me atengo a la ordenación estrófica de nuestro manuscrito. 


\begin{tabular}{|l|l|l|}
\hline \multicolumn{1}{|c|}{$\boldsymbol{V 7 0 2}$} & \multicolumn{1}{c|}{$\mathbf{S r 7 9 4}$} & \multicolumn{1}{c|}{ Or850? } \\
\hline 4h sino todo vino & sino vinagre hecho de vino & sino todo beber vino. \\
\hline 6g y el višnap & y el višnap bien hecho & cuanto más el višnap \\
\hline 7d y tengas alegría & y tengamos alegría & y tengas muncha alegría \\
\hline 20a La acraña & [omite estrofa] & 8a Si dećís por la acraña \\
\hline 9h con el vino & para beberla con el vino & $\begin{array}{l}\text { 17h para el bebedor de } \\
\text { vino }\end{array}$ \\
\hline 19h sin beber vino & que haće beber el vino & $\begin{array}{l}\text { 22h y con ella se bebe el } \\
\text { vino }\end{array}$ \\
\hline
\end{tabular}

Pero, por su parte, tampoco se libra Or850? de la cortedad de varios versos fruto de la omisión de palabras lo que hace que en ocasiones queden sin sentido. Tal es el caso, por ejemplo, de sus «por es alabada» (v. 9c), «y la es mentada» (v 9e), frente a las formulaciones de V702 «por esto es alabada» (24c) y «la no fan es enmentada» (v. 24e).

Veamos ahora cómo se reformula para bien la ya aludida conflictiva estr. 17 de $V 702$.

\begin{tabular}{|c|c|c|}
\hline V702 estr. 17 & Sr794 estr. 17 & Or850? estr. 21 \\
\hline $\begin{array}{l}\text { El limón le respondió: } \\
\text { «Yo te digo que so su } \\
\text { primo hermano»; } \\
\text { y un poco demaśiado } \\
\text { alabado el Aḅastado } \\
\text { que crió tal fruto llano, } \\
\text { y de dolientes y de sanos } \\
\text { de todos es alabado } \\
\text { azúcar polvoreado, } \\
\text { enpero corta el vino. }\end{array}$ & $\begin{array}{l}\text { El limón le respondió: } \\
\text { "Yo so su primo } \\
\text { hermandado; } \\
\text { y un poco más do yo } \\
\text { loores al Aḅastado, } \\
\text { que a mí me crió } \\
\text { para dolientes lo callo». } \\
\text { Con azucre espolvoreado, } \\
\text { enpero corta mucho el } \\
\text { vino. }\end{array}$ & $\begin{array}{l}\text { El limón, su primo } \\
\text { hermano, } \\
\text { un poco y demaśiado, } \\
\text { que lo tomáš en la mano } \\
\text { y alabáš a el Aḅastado } \\
\text { de el doliente y de el sano } \\
\text { de todos es alabado } \\
\text { azúcar polvoreado; } \\
\text { enpero corta el vino. }\end{array}$ \\
\hline
\end{tabular}

En este caso nuestro manuscrito y de forma diferente a $\mathrm{Sr} 794$ consigue reestructurar la estrofa, recomponiendo la rima en -ano en versos impares y en -ado en versos pares, y eliminando la excesiva longitud de los vs. $17 \mathrm{~b}-\mathrm{c}$ de $V 702$.

A los ejemplos señalados podemos sumar la corrección de alguna mala formulación de V702, como es el caso de «que la haćen en conservada» (v. 18d), que ya se corregía en $\operatorname{Sr} 794$ con su «que la haćen conservada», formulación que repite $\operatorname{Or} 850$ ? (v. 16d). 
2.5.3. Omisión de palabras y reformulación de frases no comprensibles

Como ya decía en Debate (pp. 515-517) un buen número de los cambios de $S r 794$ parecen derivarse de la necesidad de reformular lo que en V702 carece de sentido o resulta de difícil comprensión; eso mismo parece pasar en Or850? Veamos algunos ejemplos.

Entre las variedades de granada se menciona en $V 702$ (v. 24e) la no fan, palabra que intentaba explicar en Debate (nota 43) y que Or850? (v. 9e) ha omitido (la estrofa no figuraba en $\mathrm{Sr} 794$ ).

En relación con el pepino se dice en $V 702$ y en $\operatorname{Sr} 794$ (vs. 14e-f) «es comida con repośo, / atentá con corteśía», lo que en Or850? (vs. 20e-f) se reformula «y comerlo con repośo, / y tamién con corteśía», resultando ambos versos algo más comprensibles que en la base.

En $V 702$ (v. 11c) el albaricoque dice de sí mismo «desde que me conocí» -muy similar en Sr794-, frase que en Debate (nota 21) trataba de explicar diciendo: «Quizá quiera decir "Desde que me di a conocer"». En Or850? el verso se cambia en «deśde que yo nací», formulación próxima a la de $V 702$ (v. 18c) «oí desde que nací», verso que, por otra parte en Or850? (v. 16c) resulta ser «oí dende nací».

En relación con la mora, leemos:

\begin{tabular}{|l|l|l|}
\hline \multicolumn{1}{|c|}{ V702 vs. 10c-d } & \multicolumn{1}{|c|}{$\boldsymbol{S r 7 9 4}$ vs. 10c-d } & \multicolumn{1}{c|}{ Or850? vs. 14c-d } \\
\hline $\begin{array}{l}\text { ậuntemos con la señora } \\
\text { pera reṿivir a la muerta }\end{array}$ & $\begin{array}{l}\text { âjunte[mos] con la señora } \\
\text { y comer a la muerta }\end{array}$ & $\begin{array}{l}\text { juntos con la señora } \\
\text { que retorna alma muerta }\end{array}$ \\
\hline
\end{tabular}

La incomprensible formulación de la base en v. 10d, aún empeorada en $\operatorname{Sr} 794$, parece ahora algo más humana, entendiendo que una señora es capaz de revivir el alma de su acompañante.

2.5.4. Otras reformulaciones que mejoran lo dicho en $V 702$

Aunque comprensibles en $V 702$, parecen mejor formuladas algunas frases de $O r 850$ ?, así, por ejemplo: «y no veamos manćía» (v. 7f) frente a «y no vea tu manćilla» de $V 702$, ya que, al introducir el veamos, el hablante se implica en un deseo común, no dejando solo a su interlocutor ante la desgracia. Y están mejor escandidos otros versos 
como «cuando está bien asadica» (v. 24d), «a todos arefresquí» (v. 18c), «sobre todo es cośa sana» (v. 9f) frente a sus paralelos de V702 y de $S r 794$ «cuando es asadica» (v. 21d), «a todo el mundo refresquí» (v. 15c), y «siendo que es cośa sana» (v. 24f).

Varios cambios afectan a frases bien formuladas en $V 702$, pero en las que por algún motivo la tradición ha sentido la necesidad de cambiar. Así, hablando de la lechuga, se dice en V702 (v. 3c) «y es fresca y rośada», raro color lechuguil que ya en $\mathrm{Sr} 794$ se cambiaba en un más lógico «fresca, bien arancada», y que ahora se formula «y es fresca y donośa». Al hablar de la guinda, el insustancioso verso «es cuanto más mejorada» de $V 702$ (v. 6f) ya quedaba mejor formulado en el más expresivo de $S r 794$ «es mejor que naranjada», que en Or850? se cambia en «es cośa muy alabada»; y asimismo al hablar del higo suena mejor el «ni tú ni tus parientes» de $S r 794$, formulación a la que se suma $O r 850$ ? (v. 13f), que el cacofónico «ni tú, menos tus parientes» de $V 702$ (v. 23f). Al hablar de la manzana leemos en $V 702$ (v. 9f) y también en $S r 794$ «en frío y en calor», formulación que resulta más poética en $O r 850$ ? «si en frío, si en calor» (v. 17f), basándose en la estructura de $V 702$ para su verso 9 d «si en fruta, si en flor». No parece haberle gustado a nuestro manuscriba el ya señalado caso del cornejo que en V702 (v. 20c) «aỵolta los dientes», es decir, que da dentera, y que en $O r 850$ ? es «traba como la cacia», es decir, estriñe. Y también puede deberse a un extraño colorido el cambio, hablando de la castaña, de «si es muy rośadica» en V702, casi igual formulado en $S r 794$ (v. 21f / 20f) por «se haće una cośa rica» de Or850? (v. 24f).

Resulta también interesante la variante que presenta Or850? «que en cada fruta y fruta» (v. 1g) frente a «que en cada copla y copla» de la estrofa paralela de V702 y Sr794. Como explicación se me ocurre que nuestro manuscriba haya querido obviar la repetición de este verso que formulado de forma similar -«que cada copla y copla»- reaparece en $V 702$ y $S r 794$ (v. $2 \mathrm{~g}$ ).

A todo ello hay que sumar cambios que podemos considerar invenciones de nuestro manuscriba para las que no encuentro justificación, como, por ejemplo, su «En la meśa odrenada» (v. 24a) que sustituye a «Entrando la inviernada» de V702 y $\operatorname{Sr} 794$ (v. 21a). 


\subsubsection{Cambios a peor}

Sin embargo, con una relativa frecuencia los cambios de Or850? son para peor; me limitaré a dar algunos ejemplos. Hablando de las cerezas, en los más poéticos por más sugeridores vs. 5g-h de $V 702$ «ajuntemos, mi hermano, / con un suraí ['odre'] de vino», se han precisado innecesariamente las acciones verbales tanto en $\mathrm{Sr} 794$ como en $\operatorname{Or} 850$, reformulándose «asentemos, mi hermano, / y comámola con vino» en el primero y «asentemos, mis hermanos, / y roćialmeldas con vino» en el segundo. Sobre los melocotones en V702 (v. 13g) se dice que «por preśente las mandan», mientras que en Or850? (v. 10g) leemos un incomprensible «por gozos amores ama». Y también empeora el cambio del expresivo verso de V702 (v. 18g) «-tú di no, yo digo sí-», que en Or850? se formula de forma un tanto abstrusa «tú da, yo diré sí» (v. 16g); recordemos que en este caso $\operatorname{Sr} 794$ se salía por la tangente con su formulación «con un vaśico de raquí crimićí».

Y, como también indicaba en Debate (pp. 517-518) en relación con $\operatorname{Sr} 794$, quiero señalar un cambio que me parece especialmente significativo y que podría justificarse por autocensura. Al hablar de las ciruelas se dice:

\begin{tabular}{|c|c|c|}
\hline V702 estr. 12 & Sr794 estr. 12 & Or850? estr. 15 \\
\hline $\begin{array}{l}\text { La cirigüela más y más, } \\
\text { sino que aỵolta los dientes, } \\
\text { enṿiarlas con amigas } \\
\text { y primas y parientes; } \\
\text { las señoras y las damas } \\
\text { sienpre las tienen en } \\
\text { mientes } \\
\text { dientro de sus almas } \\
\text { porque les agrada el vino. }\end{array}$ & $\begin{array}{l}\text { La sardela, mi hermanica, } \\
\text { es buena para las gentes } \\
\text { y que sea saladica } \\
\text { y comerla con parientes; } \\
\text { la señora y la rica } \\
\text { sienpre las tienen en } \\
\quad \text { mientes } \\
\text { y dientro de su almica } \\
\text { porque es meźé con el vino. }\end{array}$ & $\begin{array}{l}\text { La ćirgüela es más agrica, } \\
\text { sino que ṿolta los dientes, } \\
\text { enṿialda con damas } \\
\text { a primas y a parientes; } \\
\text { los señores y las damas } \\
\text { todos los tienen en mientes } \\
\text { y de adientro de sus [sic] } \\
\text { porque les corta el vino. }\end{array}$ \\
\hline
\end{tabular}

Lo que se dice en $V 702$ es que las amigas (v. 12c) y las primas y parientes (femeninas) (v. 12d) envían las ciruelas como regalo, y que las señoras y las damas (v. 12e) las tienen muy en cuenta y dentro de sus corazones (vs. 12f-g) «porque les agrada el vino», frase -como ya decía en Debate- de cuya primera lectura se desprende que son las señoras las que se perecen por el vino y en la que sólo tras una relectura se puede entender que las ciruelas van bien con el vino, quedando en cualquier 
caso planeando por la cabeza del lector el trinomio ciruelas + señoras + vino.

Resulta más misógina de contenido las paralelas estrofas de $\mathrm{Sr} 794$ y de Or850? que es la que ahora nos interesa. En su v. 15e las señoras de la base se han trocado en señores, aunados estos y las damas en el todos de v. 15f, quienes, si las tienen muy en cuenta y dentro de sus corazones (vs. 15f-g), no es «porque les agrada el vino», sino por todo lo contrario: «porque les corta el vino», es decir, porque les impide beber.

\section{Conclusiones}

Ya al ocuparme en Debate (pp. 505 y 523) de V702 decía que su deteriorada versión apunta a un origen más antiguo y que su manuscriba la copiaría probablemente de otro manuscrito. Y al hablar de $S r 794$ suponía (p. 512) que David Bajar Hakohén se basó en el texto de su antepasado «mientras hacía correcciones con el propósito de recomponer la añeja versión».

Cabe ahora especular sobre la versión que ahora publico. Sin duda, y como en el caso de V702, nos encontramos ante un texto producto de la copia de otro manuscrito anterior, y ello lo muestra la abundancia de tachones y correcciones que en él encontramos, muchos de ellos producto de saltos de ojo del manuscriba.

Presenta además Or850? otras peculiaridades. Como ya he dicho arriba, faltan algunos versos, y también desaparecen palabras que dejan las frases inconclusas; pero no puedo saber si tales omisiones se deben a incompetencia de nuestro manuscriba o si tales lagunas ya estaban en el manuscrito que se copiaba. Sin embargo, en lo referente a la omisión de palabras yo culparía a nuestro reproductor, ya que algunas parecen fruto de falta de atención al escribir, como, por citar un solo ejemplo, la ausencia de almas en v. $15 \mathrm{~g}$, paralelo de v. $12 \mathrm{~g}$ de las otras dos versiones.

Desde el punto de vista textual y como ya decía arriba, resulta obvio que el manuscrito que se ha copiado está mucho más próximo a $V 702$ que a $S r 794$, ya que nuestro texto no recoge ninguna de las muchas variantes que el último presenta frente al primero, y además sí aparecen en Or850? las estrs. 20 y 24 de V702 que, como ya he dicho, no figuran en $\mathrm{Sr} 794$. 
Y, por último, tampoco puedo saber a qué responde la ordenación de estrofas de Or850?: ¿estaba ya así en el manuscrito copiado o se trata de una revoltina de nuestro manuscriba?

En contra de lo que decía en Debate, afirmo sinceramente ahora que espero no volverme a encontrar con otra nueva versión de esta copla. Dejo para otros colegas tal ventura y con su vino se la beban.

\section{GLOSARIO}

amá (tc. ama) 'pero'.- atemar (cfr. hb. ת tam) 'acabar, finalizar'.- cacia (esp. acacia) 'endrino, ciruela silvestre'.- ciciones (esp. sing. cición) 'tercianas'; corríjase la grafía sisiones de Debate.- chuflar 'beber', vid. nota 29.- dende 'desde'.- Lapsekí (tc. Lâpseki): ciudad de la Turquía asiática en los Dardanelos al norte de Çanakkale.- loria 'gloria'.- maḥmurlic (tc. mahmurluk) 'resaca después de una borrachera'.- múšcula (tc. müşküle): cierto tipo de baya.- preta 'negra'.- trabar 'producir estreñimiento, estreñir'.- višnica (tc. vişne) dim. 'guindita'.- yocsoí: vid. nota 14 y aprt. 2.2.

Recibido: $17 / 07 / 2012$

Aprobado: 12/12/2013 